\title{
A pilot study: mindfulness meditation intervention in COPD
}

\author{
This article was published in the following Dove Press journal: \\ International Journal of COPD \\ 2 March 2015 \\ Number of times this article has been viewed
}

\author{
Roxane Raffin Chan' \\ Nicholas Giardino ${ }^{2}$ \\ Janet L Larson ${ }^{3}$ \\ 'College of Nursing, Michigan State \\ University, East Lansing, ${ }^{2}$ Department \\ of Psychiatry, ${ }^{3}$ School of Nursing, \\ University of Michigan, Ann Arbor, \\ MI, USA
}

\begin{abstract}
Living well with chronic obstructive pulmonary disease (COPD) requires people to manage disease-related symptoms in order to participate in activities of daily living. Mindfulness practice is an intervention that has been shown to reduce symptoms of chronic disease and improve accurate symptom assessment, both of which could result in improved disease management and increased wellness for people with COPD. A randomized controlled trial was conducted to investigate an 8-week mindful meditation intervention program tailored for the COPD population and explore the use of breathing timing parameters as a possible physiological measure of meditation uptake. Results demonstrated that those randomized to the mindful meditation intervention group $(\mathrm{N}=19)$ had a significant increase in respiratory rate over time as compared to those randomized to the wait-list group $(\mathrm{N}=22)(P=0.045)$. It was also found that the mindful meditation intervention group demonstrated a significant decrease in level of mindfulness over time as compared to the wait-list group $(P=0.023)$. When examining participants from the mindful meditation intervention who had completed six or more classes, it was found that respiratory rate did not significantly increase in comparison to the wait-list group. Furthermore, those who completed six or more classes $(\mathrm{N}=12)$ demonstrated significant improvement in emotional function in comparison to the wait-list group $(P=0.032)$ even though their level of mindfulness did not improve. This study identifies that there may be a complex relationship between breathing parameters, emotion, and mindfulness in the COPD population. The results describe good feasibility and acceptability for meditation interventions in the COPD population.
\end{abstract}

Keywords: integrative therapies, contemplative therapies, breathing timing parameters, chronic obstructive pulmonary disease, pulmonary rehabilitation

\section{Introduction}

People with COPD consistently describe their dyspnea as increased work of breathing and air-hunger, identifying air-hunger as the factor most limiting their ability to actively engage in life. ${ }^{1}$ For persons with COPD, anxiety can trigger hyperventilation. Once triggered, hyperventilation leads to a sensation of air-hunger, which is anxiety provoking. This then establishes a feedback loop of anxiety and dyspnea. ${ }^{2}$ The presence of anxiety disorders in persons with pulmonary disease is higher than that of the general population, ${ }^{3}$ and is associated with more negative appraisal of dyspnea ${ }^{4}$ and less participation in rehabilitative programs. ${ }^{5}$

Current research indicates that the active practice of meditation improves the perception of interoceptive information, ${ }^{6}$ including the accuracy of respiratory load. ${ }^{7}$ This effect may be mediated by lowering chemosensitivity to $\mathrm{CO}_{2}$ and providing faster recovery after sensory processing has occurred. ${ }^{8,9}$ For persons with COPD and anxiety, meditation may improve their ability to detect and monitor respiratory load and immediate ventilatory needs, resulting in improved mental acuity and
Correspondence: Roxane Raffin Cha College of Nursing, Michigan State University, 1355 Bogue Street,

Room \#C242, East Lansing, MI 48824-1317, USA

Tel +I 7344780170

Email rchan@MSU.edu submit your manuscript | www.dovepress.com

Dovepress

http://dx.doi.org// 0.2147/COPD.S73864
International Journal of COPD 2015:10 445-454 
participation in self-care management and activities of daily living. ${ }^{10-12}$ Following participation in an 8-week program of Mindfulness-Based Stress Reduction (MBSR), Mularski et al did not find any improvement in a 6-minute walk or in COPD symptom burden and quality of life as measured by the total Saint George Respiratory Questionnaire. ${ }^{13}$ Mularski et al modified the standard MBSR program to included Herbert Benson's relaxation response breathing skill, ${ }^{14}$ and taught the skill of pursed lip breathing. Because this study was conducted through the Veterans Administration, it involved a particular population of persons with COPD. Overall, they experienced a $41 \%$ drop-out rate. ${ }^{13}$

The purpose of this research was to investigate a mindfulness meditation intervention specifically adapted for persons with COPD and to explore changes in breathing timing parameters in response to meditation practice. This mindfulness meditation intervention de-emphasized breathing as a focus of meditation, assisted subjects to identify personal and perhaps spiritual mantras, and provided positive breathing experiences. We examined the feasibility and acceptability of a mindfulness meditation intervention for persons with COPD using the MBSR structure and determined preliminary effects on breathing parameters, anxiety sensitivity, level of mindfulness, and COPD symptom burden. It has been demonstrated that breathing timing parameters change in response to meditation at rest over time in healthy individuals ${ }^{15}$ and in individuals with heart failure. ${ }^{16}$ This change can perhaps be used as a measure of meditation uptake. To date, no study has looked at how the experience of meditation impacts breathing timing parameters at rest in the COPD population.

\section{Methods}

\section{Study design}

This study was a randomized controlled trial with participants randomly assigned to a mindful meditation intervention group or a wait-list control group. Baseline measures were taken within 1 week prior to the beginning of the intervention. Follow-up measures were taken within 1 week of completion of the 8-week long intervention. No payment was offered to the participants for their participation in the study. To make travel times shorter for the participants, classes were held in their respective pulmonary rehabilitation locations under the complete direction of the primary researcher. All participants agreed to participate in the study and completed an informed consent form. The study was approved by a local institutional review board and registered in www.clinicaltrials.gov as study number NCT01577329.

\section{Participants}

Participants were recruited via informational flyers in physicians' offices, clinics, and pulmonary rehabilitation centers, or by physician referral. Inclusion criteria were as follows: physician diagnosis of COPD, able to read and write English, and having reliable transportation. Exclusion criteria included the presence of any active lung disease other than COPD. Fifty-one participants were assessed for eligibility. Forty-one participants were randomized to either the meditation intervention group or the wait-list group (Figure 1).

\section{Randomization}

All participants agreed to be randomized. Stratified randomization was conducted using baseline measures of spirometry to assure participant balance in disease severity. The participant identification number, and forced end expiratory pressure in 1 second percent of predicted normal value $\left(\mathrm{FEV}_{1} \%\right)$ results were sent to an independent researcher, who assigned participants to groups by using a list of randomly generated numbers and by blocking on the $\mathrm{FEV}_{1} \%\left(<40 \mathrm{FEV}_{1}\right.$ and $\geq \mathrm{FEV}_{1} \%$ ). Those participants randomized to the wait-list control group were offered the opportunity to participate in the mindfulness meditation intervention after completion of the study. Participants in both groups continued to receive normal care, and those that were attending pulmonary rehabilitation or maintenance program continued to attend their respective programs. All participants were asked to refrain from learning or practicing any meditation other than what was taught during the mindfulness meditation intervention. Also, participants in the meditation intervention group signed a confidentiality agreement to not discuss the content of the class with fellow pulmonary rehabilitation participants.

\section{Intervention}

The mindfulness meditation intervention was comprised of eight weekly 60-minute classes of meditation and mindful movement activities that used the overall format of MBSR. Jon Kabat-Zinn developed MBSR at the University of Massachusetts and established a set manual that outlines specific meditation exercises. It is required that meditation instructors have had formal training in MBSR and a longstanding personal program of MBSR ${ }^{17}$ The mindfulness meditation intervention used in this study was conducted by a nurse who was trained in meditation, including MBSR, had taught meditation for more than ten years, and currently maintains a long-standing personal practice of meditation. Class sessions were not recorded; however, the nurse leader made extensive notes immediately after each session that 


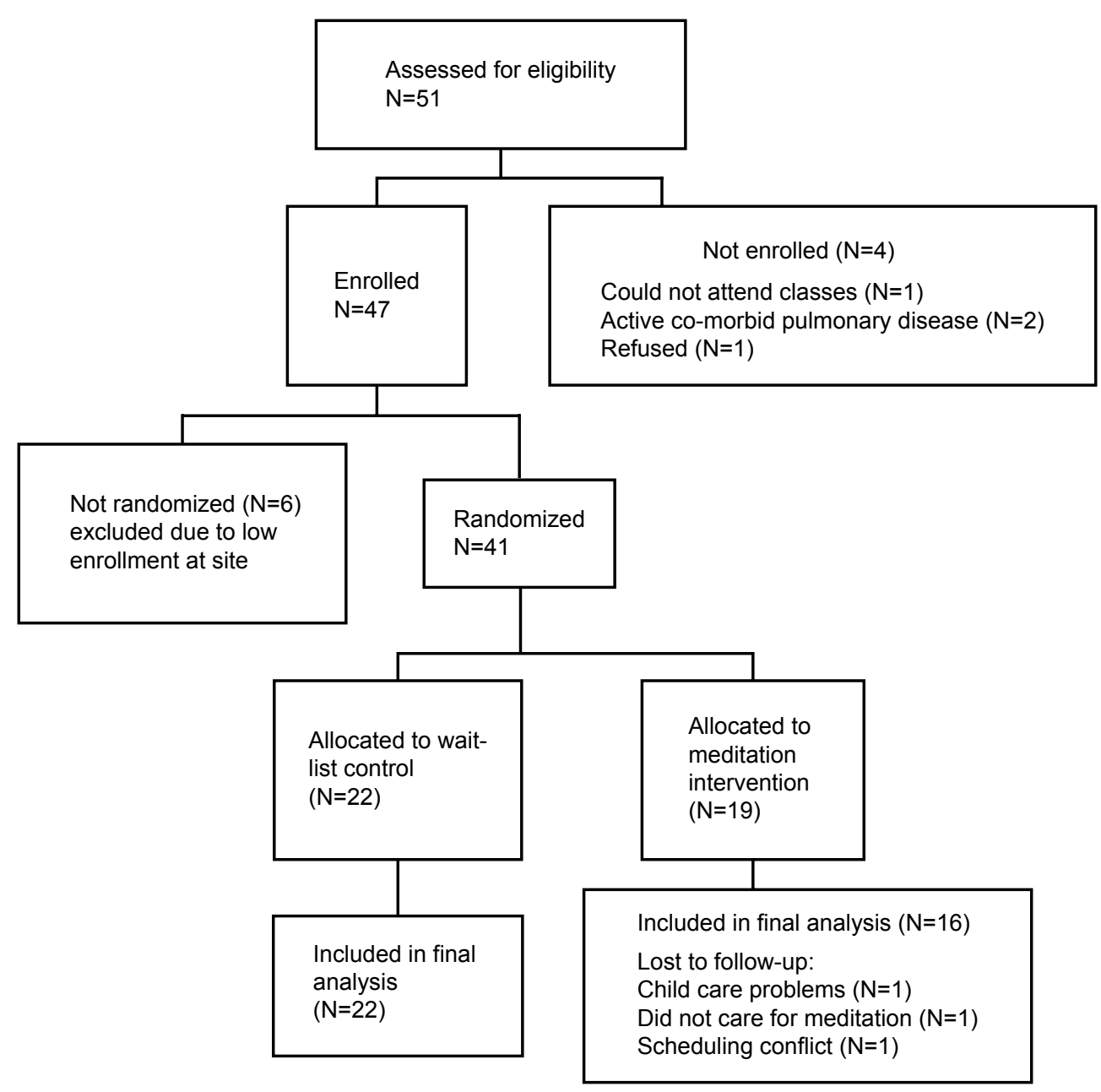

Figure I Flow diagram of participants through the trial.

were then transcribed and used to establish consistency between sites. Class sizes were set at a minimum of five and a maximum of ten participants to promote group interaction and learning. A teaching manual was developed. Weekly handouts and an audio compact disc of all meditation and mindful movement exercises were provided to each participant to be used in home practice. Due to the need for supplemental oxygen and the fatigability of persons with COPD, the class time was limited to 60 minutes. To address other issues specific to persons with COPD, the program minimized the traditional focus on the breath during the beginning meditation exercises. In an attempt to improve symptom management, a non-threatening focus on dyspnea awareness was included. Ujjayi breathing was included, and a labyrinth for walking meditation was included. Further, a spiritual focus was introduced to augment a feeling of comfort during meditation. QiGong was chosen as the meditative movement exercise, based on the expertise of the teacher leading the intervention.

\section{Reduced focus on the breath}

Concentration on areas of the body that are directly related to current illness can be anxiety provoking and can interfere with meditation. ${ }^{18}$ For this reason, meditation skills that use a focus on the breath, such as the body scan and beginning meditation, were taught with an alternative focus. The body scan, which guides persons to connect with each part of their body, often instructs participants to use the sensation of the breath to move from one body part to another. Body awareness was instead taught, using the sensation of the heart beat or visual sensation of color moving through the body. The beginning meditation skill was taught using a spiritually based mantra described below in the "Spiritual mantra" section.

\section{Spiritual mantra}

There is substantial support for the efficacy of using spiritually based mantras. ${ }^{14,19,20}$ Within the group setting, the concept of spiritual as opposed to religious was introduced. Subjects 
then participated in an exercise that facilitated identification of a personal word, image, or phrase that conveyed a sense of comfort, to be used as a meditation mantra. The Mantram Handbook was used as a guide to conducting this group work. ${ }^{21}$ Subjects were not required to share their personal mantra.

\section{Focus on dyspnea}

The original MBSR program includes one class devoted to assisting participants develop a healthy detached nonjudgmental awareness of negative emotions. ${ }^{22}$ This session was adapted to focus on the sensation of dyspnea. While taking steps to address their dyspnea, subjects were asked to describe those situations during which they became dyspneic, and the emotions that occurred before during and after those situations. Group time was used to share these experiences and to process the emotions that accompanied periods of dyspnea.

\section{Qigong}

Traditionally, all schools of meditation included teachings that develop the student's ability to connect the experience of their physical body to the larger experience of the universe through the practicing of yoga, Tai Chi, or Qigong. ${ }^{23}$ Qigong was selected as the mindfulness movement activity, because the meditation instructor had formal Qigong training and a well-developed personal Qigong practice. This then alleviated the need for two instructors. Qigong is a fluid practice that can be done standing or seated, has been shown to improve physiological functions, ${ }^{24,25}$ and has been shown to be beneficial for persons with COPD. ${ }^{26}$ Four Qigong exercises were included in this mindfulness meditation intervention: Lung wake up, Lung release, Qigong walking, and Lung meditation.

\section{Ujjayi breathing}

Ujjayi breathing is a diaphragmatic breath that first fills the lower belly, rises to the lower rib cage, and finally moves into the upper chest and throat. ${ }^{27}$ Inhalation and exhalation are both done through the nose. The "ocean sound" is created by slightly constricting the glottis as air passes in and out. The diaphragm is then used to control the length and speed of the breath, strengthening the diaphragm, and bringing increased awareness and enjoyment to the process of breathing. The inhalations and exhalations are equal in duration, and are controlled in a manner that causes no distress to the practitioner.

\section{Labyrinth}

Persons with COPD often become short of breath when walking, requiring them to pace their daily activities. Walking is also a major diagnostic tool that lets the person with COPD and the health care provider know if the disease is advancing or under control. ${ }^{28,29}$ Thus, walking can be associated with many negative emotions. For this reason, labyrinth walking was selected to allow subjects to decrease their fearful anticipation of walking by developing a meditative focus while walking slowly. The concept of walking slowly with a meditative focus was combined with the concept of movement following the breath that was introduced during the session on Qigong. This provides, at the least, an experience of walking without the need to worry about speed or distance and, at the most, a beautiful sensation of coming to a place of being centered and calm.

\section{Measures}

\section{Breathing parameters}

Breathing timing measures were measured using inductive plethysmography with a portable dual elastic band system (ClevMed bio-radio system). Measures were taken for 10 minutes under quiet conditions, in a seated position after a 5-minute rest. Breathing parameter data were reduced with Vivonoetic's Vivosense ${ }^{\circledR}$ software. The Qualitative Diagnostic Calibration routine was used to provide unequal weightings for each respiratory compartment. ${ }^{30}$ The use of Qualitative Diagnostic Calibration has been shown to be accurate and reliable for measuring breathing timing parameters. ${ }^{31}$ Respiratory timing measures included: respiratory rate; respiratory rate variability, calculated using the root mean square of successive respiratory rates over a specific time period; expiration time; and synchronization of chest/abdomen movement (absolute phase angle).

\section{The revised Anxiety Sensitivity Index}

Sensitivity to the sensation of anxiety was measured with the revised Anxiety Sensitivity Index-3 (ASI-3), which is an 18-question refined version of the original ASI. ${ }^{32}$ The ASI-3 correlated with other self-reported measures of anxiety and sensitivity without sex differences and with a good scale of reliability. ${ }^{33}$ In persons with COPD, the ASI-3 was predictive of the degree of dyspnea perceived while breathing against resistive loads. ${ }^{5}$

\section{The Chronic Respiratory Disease Questionnaire}

COPD symptom burden was measured with the Chronic Respiratory Disease Questionnaire (CRQ). The questionnaire contains four scales that measure dyspnea during common daily activities, fatigue, mastery for self-care of 
COPD symptoms, and emotional function. Each scale is rated on a 1-7 Likert scale, with higher scores indicating fewer symptoms. ${ }^{34}$ This instrument is widely used, and there is evidence to support its reliability and validity. ${ }^{35}$

\section{The Freiburg Mindfulness Inventory}

The Freiburg Mindfulness Inventory (FMI) is a 14-item questionnaire that measures a single holistic concept of mindfulness that is comprised of the distinct facets of present moment awareness, body awareness, and self-acceptance. ${ }^{36} \mathrm{It}$ assesses the subject's level of mindfulness and their ability to tolerate negative sensations on a 1-4 Likert scale, with higher numbers reflecting a greater degree of mindfulness. ${ }^{37}$ The FMI demonstrated good reliability with an alpha of 0.93 , and inter-item correlations of $0.32 .{ }^{36}$

\section{Feasibility and acceptability}

The feasibility and acceptability of the mindfulness meditation intervention was assessed using class attendance and information from weekly journals that asked participants to record how many minutes they practiced each day. The journals also included two questions to expand our understanding of how persons with COPD view meditation practice. The first question assessed helpfulness of meditation using a 0-3 Likert scale, with 0 being "not at all" and 3 being "a great deal": "I felt that I benefited from my meditation practice this week." The second question assessed each participant's level of rumination using a 0-3 Likert scale, with 0 being "only occasionally" and 3 being "a great deal of the time": "Worrying thoughts go through my mind."

\section{Statistical analysis}

Baseline measures were evaluated using the Student's $t$-test for differences between groups. Pearson product moment correlation coefficient (Pearson's $r$ ) was used to analyze the correlation between respiratory and survey measures. The effects of the intervention were analyzed using a one-way analysis of variance (ANOVA) with repeated measures for the effect of time. ${ }^{38}$ Data are presented as mean (standard deviation). At an $80 \%$ power level, with a $5 \%$ type I error rate, the power analysis suggested 29 participants per intervention arm to detect a medium effect size. Please note that the power analysis accounted for a $20 \%$ drop-out rate in enrollment, as identified in previous studies for this population. ${ }^{39}$ All statistical analyses were implemented using SPSS version 22, and the power analysis was implemented using PASS software.

\section{Results}

\section{Baseline results}

After assessing for eligibility, the study consisted of 41 participants, 19 in the intervention group and 22 in the wait-list group (Figure 1). A total of 35 participants completed all pre-test and post-test measures. The participants were mostly female, 27/41, with a mean age of 69.5 (7.9) years and a mean of 6.78 (5.84) years since diagnosis with COPD. The wait-list control group was mostly men (19/22), and the meditation intervention group was evenly divided between men and women (8/19). Disease severity was assessed according to the stages of the Global Initiative for Chronic Obstructive Lung Disease (GOLD). ${ }^{40}$ At baseline, $2 \%$ of participants were assessed as GOLD stage 1, 37\% were assessed as GOLD stage 2, 41\% were assessed as GOLD stage 3, and $20 \%$ were assessed as GOLD stage 4 . This was a highly functional group with $20 \%$ currently attending pulmonary rehabilitation and another $70 \%$ attending self-pay maintenance programs at a pulmonary rehabilitation center, while $4 \%$ reported working-out at non-pulmonary rehabilitation sites such as community or private gyms. Only $6 \%$ of the participants had never attended and/or were not currently attending any type of pulmonary rehabilitation program. For those participants who reported participating in pulmonary rehabilitation or some type of exercise program, 22 reported attending two times a week, 15 reported attending three times a week, and one participant reported working out four times a week. Those participants active in formal pulmonary rehabilitation or maintenance programs attended one of three area programs affiliated with large health care systems and certified by the American Association of Cardiovascular and Pulmonary Rehabilitation.

Of the 41 randomized participants, $64 \%$ had no experience with any type of meditation and $23 \%$ had very little experience, which was mostly reading about meditation or trying meditation on their own without instruction. Eleven percent had taken some type of meditation class. Those who had experienced some type of meditation class reported taking a class in Transcendental Meditation sometime during the 1960s or early 1970s. Except for one participant, no others reported that they were successful in developing a personal practice of meditation, and none were currently meditating. One participant in the wait-list control group had personal practice of meditation; however, because meditation practice can vary a great deal, she was included in the study. As a check, all measures were run with and without this participant included, and the results were not different for any of the outcome measures. 
At baseline, participants in the meditation intervention group had significantly less dyspnea as compared to the wait-list group (4.86 [1.69] compared to 3.84 [1.31], respectively; $P=0.04$ ) and significantly less anxiety sensitivity as compared to the wait-list group (14.44 [10.23] compared to 25.45 [15.62] respectively; $P=0.02$ ). There was no difference between the groups in terms of FEV1\% predicted $(P=0.86)$.

\section{Feasibility and acceptability}

A review of class participation indicated that participants attending classes were able to attend the entire 60 minutes of each class that they attended, participated fully in each activity, and were willing to complete homework assignments. Overall, the majority of participants in the meditation treatment group attended six or more meditation classes $(12 / 19)$. Five participants attended regularly, and then stopped attending. Three participants attended only the first three classes. Two of those reported no cause or reason for not attending. The third participant was hospitalized for an aborted lung transplant, and then reported problems with child care arrangements. Two participants stopped attending classes after four and five classes, respectively. One of these left on vacation and the other sustained a fall, requiring treatment. All other participants missed isolated classes because of a variety of scheduling difficulties. During the study, no participant reported being hospitalized due to COPD exacerbation. An average of 13 subjects turned in journals each week. Reported time spent meditating per meditation attempt increased over the 8 -week course, with the mean number of days meditating per week remaining high (five out of seven) (Figure 2).

Emotional function and perceived helpfulness of meditation correlated with the number of classes attended. The baseline measure of emotional function was positively correlated with number of classes attended $(r=0.35, P=0.05)$. From the weekly journals, the question regarding perceived helpfulness of meditation significantly correlated with the number of days per week that participants reported having meditated $(r=0.36, P=0.05)$.

\section{Results of the statistical model}

In group comparisons, participants in the meditation intervention group demonstrated a statistically significant increase in respiratory rate at the end of the meditation intervention compared to the wait-list control group (15.93 [2.82] compared to 21.30 [3.05] at the end of intervention vs 17.18 [6.44] compared to 18.73 [4.31] at the end of intervention, respectively; $P=0.05$, partial eta-squared $\left[\eta^{2}\right]=0.13$ ). No

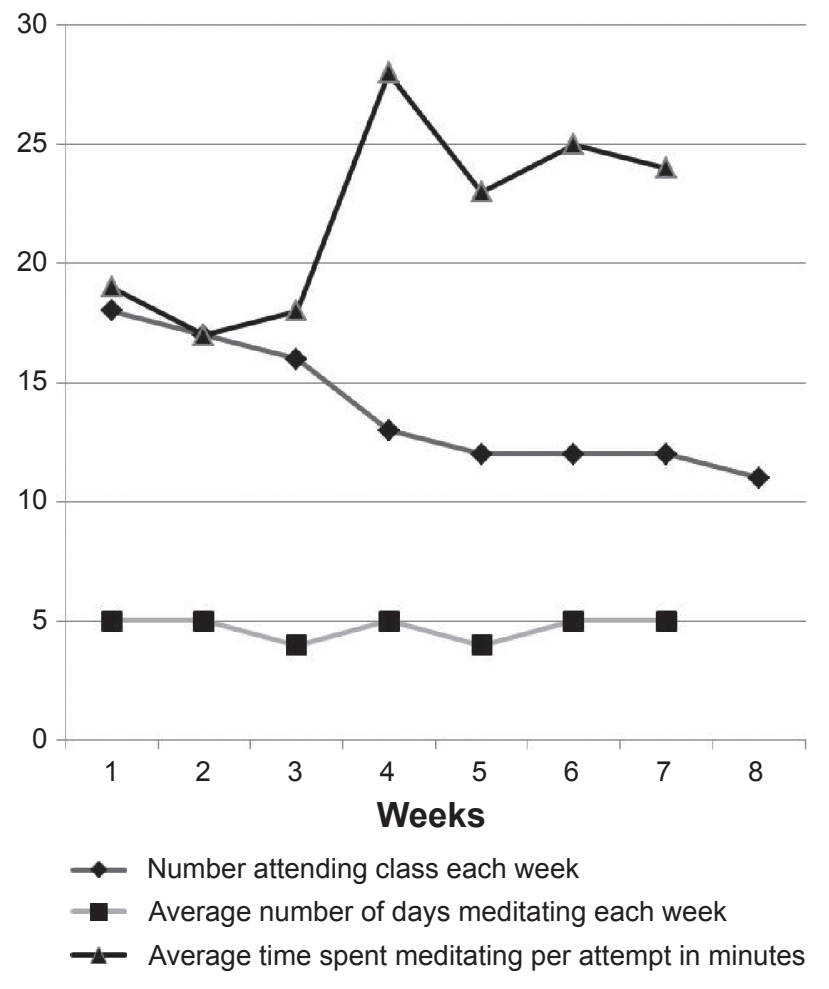

Figure 2 Participation in meditation intervention.

changes were seen in expiratory time, absolute phase angle or respiratory rate variability. The change in respiratory rate was not correlated with change in the ASI-3 $(r=0.23, P=0.46)$, dyspnea ( $r=0.24, P=0.42)$, emotional function $(r=0.20$, $P=0.57)$, mastery $(r=0.38, P=0.20)$, fatigue $(r=0.01, P=0.97)$ or the FMI $(r=0.24, P=0.43)$. However, when comparing only those participants in the meditation intervention group who had completed six or more classes ( $\mathrm{N}=12)$, it was found that respiratory rate did not significantly increase in comparison to the wait-list group.

The ASI-3, the dyspnea scale, and the fatigue scale of the CRQ did not change between groups over time; however, the FMI significantly decreased in the meditation intervention group in comparison to the wait-list control group over time (42.75 [8.10] compared to 40.43 [8.25] at the end of intervention vs 38.48 [8.70] compared to 40.09 [7.84] at the end of intervention, respectively; $P=0.02, \eta^{2}=0.15$ ). Emotional function and mastery showed a trend toward improvement in the meditation intervention group as opposed to the wait-list control group. Emotional function improved by the end of meditational intervention in both the meditation intervention and wait-list control groups (5.08 [1.26] at baseline compared to 5.42 [1.05] vs 4.33 [1.12] at baseline compared to 4.42 [1.06], respectively; $P=0.06, \eta^{2}=0.12$ ). Mastery also improved by the end of meditation intervention in both the 
meditation intervention and wait-list control groups (5.10 [1.26] compared to 5.47 [1.25] vs 4.31 [1.36] compared to 4.09 [1.07], respectively; $P=0.06, \eta^{2}=0.11$ ). When including only those subjects that had attended six classes or more, significant improvement in emotional function was demonstrated in the meditation intervention group compared to the wait-list control group by the end of intervention (5.17 [1.45] compared to 5.61 [1.13] vs 4.33 [1.13] compared to 4.24 [1.06], respectively; $P=0.03, \eta^{2}=0.19$ ).

\section{Discussion}

Respiratory rate and FMI were the only two measures to demonstrate significant change over time between groups. However, when considering only those participants who attended six classes or more, the change in respiratory rate lost significance. Another measure which demonstrated different results based on class attendance was the emotional function scale of the CRQ. When considering participants who attended six or more classes, the emotional function levels improved significantly over those enrolled in the wait-list group. Further, there appeared to be a relationship between baseline emotional function and the ability to attend meditation classes. The change in respiratory time and FMI overall implies that the mindfulness meditation intervention was not successful. Investigation of the change in these measures demonstrated that change occurred in a similar direction but did not correlate. This suggests a possible mediator is involved in the relationship between respiratory rate and level of mindfulness. Despite lack of outcome success, this study demonstrated good feasibility and acceptability for the mindfulness meditation intervention in the COPD population.

This study identified that respiratory pattern changes can be used as a measure of meditation intervention uptake; however, it is possible that emotions may mediate the relationship between respiratory rate and level of mindfulness. Respiratory patterns have been demonstrated to be stable over time and fluctuate in a consistent manner during changes in respiratory demand, such as exercise. ${ }^{41}$ Despite this stability, respiration patterns have been shown to change at rest in response to meditation practice in persons without pulmonary disease. After attending a meditation intervention using a focus on Ujjayi breathing, it was found that healthy persons demonstrated a decrease in respiratory rate and an increase in expiratory time. ${ }^{15}$ A group of participants with heart failure who attended an MBSR intervention also demonstrated a decrease in respiratory rate at rest that was shown to be a result of prolonged expiratory time. ${ }^{16}$ Although these studies demonstrated a change in respiratory pattern along with improved function and quality of life, they did not measure mindfulness levels..$^{15,16}$

Meditation time needed to change levels of mindfulness varies greatly between meditation studies. Although some studies identify improvements in mindfulness in a short time period, some identify the need for a longer period of meditation experience..$^{22,42-44}$ No other study of meditation in the COPD population has measured mindfulness levels, so we do not know how long it will take for persons with COPD to increase their level of mindfulness. It is important to note that persons attending the mindfulness meditation intervention were still actively learning meditation skills through week 8 and would be considered beginner meditators at the end of week 8. It is possible that the duration of the mindfulness meditation intervention and the timing of the measurements may have affected the results. When persons are learning complex skills such as mindfulness, their learning is non-linear and demonstrates the existence of phase transitions. These transitions often include critical fluctuations or periods of arrested progress that immediately precede full integration of the new complex skill. ${ }^{45,46}$ Perhaps the decrease in mindfulness demonstrated in this study represents initial phase changes. ${ }^{47}$

Mindfulness meditation, which is included in MBSR and in the mindfulness meditation intervention that was used in this study, is a complex skill. It involves learning to simultaneously become more aware of and detached from negative emotions and sensations. This may be initially overwhelming for persons with life-threatening chronic disease. In this study, subjects were taught mindfulness while learning to be more aware of their sensations of dyspnea. In the Mularski et al study, subjects were taught to be mindful of negative emotions. ${ }^{13}$ Neither study demonstrated significant improvements in symptom burden or function. However, in two recent studies involving persons with COPD, meditation interventions were used which did not include the specific skill of mindful awareness. ${ }^{26,48}$ Fulambarker et al investigated yoga combined with a mantra-style meditation and demonstrated improvement in the total Saint George Respiratory Questionnaire $(P=0.00){ }^{48}$ Chan et al used a Qigong style of mindful movement along with mantra-style meditation and demonstrated improvement in the 6-minute walk test $(P=0.03) .{ }^{26}$ Both meditation interventions, which did not include mindfulness, were much longer in duration (33 sessions and 24 sessions, respectively).

It may be that including only a non-threatening mantrastyle meditation allowed people with COPD to attend classes long enough to benefit. This is the "catch-22" of 
meditation interventions. Meditation interventions have been demonstrated to reduce anxiety, ${ }^{49}$ but high levels of anxiety and/or panic produce a barrier to participation. ${ }^{50}$ The study by Mularski et al had a very high dropout rate (41\%), which may have been impacted by the demographics of this particular population. In that study, all of the participants were older male veterans often found to have a high occurrence of Post Traumatic Stress Disorder. ${ }^{13}$ In this study, it was found that emotional function correlated with class attendance. Those with higher levels of emotional function (less anxiety and depression) were apt to attend more classes. It was also the case that participants in the meditation intervention group had low anxiety sensitivity as measured by the ASI-3. The mean ASI-3 score for the meditation intervention group in this study was 15.93 (2.82) and as such did not reach the level that is indicative of a diagnosis of anxiety or panic. ${ }^{51}$ This study helps to identify that there is a complex relationship between breathing timing parameters, emotional function, and mindfulness in people with COPD.

To date, research on meditation in the COPD population demonstrates a need to introduce the concepts and practice of meditation in a manner that allows participants to progress at their own pace. Ongoing drop-in meditation classes that focus on simple mantra meditation and meditative movement would be more acceptable, and as such, more effective. This design will provide a non-threatening class format and allow persons with COPD to adjust class attendance to accommodate individual health care needs. Research indicates that the meditation skill of focused attention, such as mantra meditation, increases a person's ability to attend, lowers sympathetic activation, and increases one's ability to seek out novel situations. ${ }^{52}$ Focusing initially on this beginning skill of meditation will allow persons with COPD to participate to the level of their comfort, increasing the chances of them developing a long-term practice of meditation. Notably, participants at two research sites requested that the meditation classes continue. Staff members who already had a well-developed practice of meditation were trained to teach the mindfulness meditation classes. These classes have continued with high attendance.

\section{Limitations of the study and future research}

This study was burdened with financial limitations that resulted in a small sample size and lack of long-term follow-up. It is recommended that future research on meditation in persons with chronic disease, and in particular those with COPD, be of longer duration. It is also recommended that measures be taken post-intervention and then at 4 and
6 months' follow-up. Overall, meditation is beneficial for persons with COPD, and further research to identify more acceptable intervention protocols is warranted.

\section{Conclusion}

This study added to our understanding of how to better design meditation interventions for persons with COPD. It demonstrated that meditation classes held at pulmonary rehabilitation sites were feasible. In order to increase acceptability, future meditation interventions need to provide ongoing classes that focus on mantra-style meditation and meditative movement, without presenting emotionally-triggering skills such as mindful awareness to emotions or dyspnea. Perhaps, as persons with COPD become adept at meditation skills, these complex concepts can be added. However, for those diagnosed with co-morbid anxiety or panic, mindful awareness of emotions and dyspnea may not ever be appropriate or necessary. It is interesting that despite negative outcome results, a large number of participants continued to pursue meditation instruction. Exploration of the perceived benefits of meditation needs to be pursued with this group of individuals. This research will help identify timeframes regarding improved mindfulness, and the effect of meditation on disease management and symptom burden.

\section{Acknowledgment}

This research was conducted at the University of Michigan and supported by the National Institutes of Health (NIH) grant F31NRO12334.

\section{Disclosure}

This current paper includes some work submitted in partial fulfillment of the requirements for the degree of Doctor of Philosophy (Nursing) at the University of Michigan in 2013 by Roxane Raffin Chan as per website. The authors report no other conflicts of interest in this work.

\section{References}

1. Williams M, Cafarella P, Olds T, Petkov J, Frith P. The language of breathlessness differentiates between patients with COPD and agematched adults. Chest. 2008;134(3):489-496.

2. Stein MB. Neurobiology of generalized anxiety disorder. J Clin Psychiatry. 2009;70(Suppl 2):15-19.

3. Võgele C, von Leupoldt A. Mental disorders in chronic obstructive pulmonary disease (COPD). Respir Med. 2008;102(5):764-773.

4. von Leupoldt A, Taube K, Henkhus M, Dahme B, Magnussen H. The impact of affective states on the perception of dyspnea in patients with chronic obstructive pulmonary disease. Biol Psychol. 2010;84(1): 129-134.

5. Giardino ND, Curtis JL, Abelson JL, et al. The impact of panic disorder on interoception and dyspnea reports in chronic obstructive pulmonary disease. Biol Psychol. 2010;84(1):142-146. 
6. Slagter HA, Lutz A, Greischar LL, Nieuwenhuis S, Davidson RJ. Theta phase synchrony and conscious target perception: impact of intensive mental training. J Cogn Neurosci. 2009;21(8):1536-1549.

7. Daubenmier J, Sze J, Kerr CE, Kemeny ME, Mehling W. Follow your breath: respiratory interoceptive accuracy in experienced meditators. Psychophysiology. 2013;50(8):777-789.

8. Spicuzza L, Gabutti A, Porta C, Montano N, Bernardi L. Yoga and chemoreflex response to hypoxia and hypercapnia. Lancet. 2000; 356(9240):1495-1496.

9. Wolkove N, Kreisman H, Darragh D, Cohen C, Frank H. Effect of transcendental meditation on breathing and respiratory control. J App Physiol Respir Environ Exerc Physiol. 1984;56(3):607-612.

10. Kim YY, Choi JM, Kim SY, Park SK, Lee SH, Lee KH. Changes in EEG of children during brain respiration-training. Am J Chin Med. 2002;30(2-3):405-417.

11. Chan AS, Han YMY, Cheung MC. Electroencephalographic (EEG) measurements of mindfulness-based triarchic body-pathway relaxation technique: a pilot study. Appl Psychophysiol Biofeedback. 2008;33(1): 39-47.

12. Lutz A, Greischar LL, Rawlings NB, Ricard M, Davidson RJ. Long-term meditators self-induce high-amplitude gamma synchrony during mental practice. Proc Natl Acad Sci US A. 2004;101(46):16369-16373.

13. Mularski RA, Munjas BA, Lorenz KA, et al. Randomized controlled trial of mindfulness-based therapy for dyspnea in chronic obstructive lung disease. J Altern Complement Med. 2009;15(10):1083-1090.

14. Benson H, Klipper MZ. The relaxation response. New York: HarperCollins Publishers; 1975.

15. Villien F, Yu M, Barthélémy P, Jammes Y. Training to yoga respiration selectively increases respiratory sensation in healthy man. Respir Physiol Neurobiol. 2005;146(1):85-96.

16. Robert McComb JJ, Tacon A, Randolph P, Caldera Y. A pilot study to examine the effects of a mindfulness-based stress-reduction and relaxation program on levels of stress hormones, physical functioning, and submaximal exercise responses. J Altern Complement Med. 2004;10(5): 819-827.

17. Kabat-Zinn J. An outpatient program in behavioral medicine for chronic pain patients based on the practice of mindfulness meditation: theoretical considerations and preliminary results. Gen Hosp Psychiatry. 1982; 4(1):33-47.

18. Foley E, Baillie A, Huxter M, Price M, Sinclair E. Mindfulness-based cognitive therapy for individuals whose lives have been affected by cancer: a randomized controlled trial. J Consult Clin Psychol. 2010;78(1): 72-79.

19. Wachholtz AB, Pargament KI. Migraines and meditation: does spirituality matter? J Behav Med. 2008;31(4):351-366.

20. Wachholtz AB, Pargament KI. Is spirituality a critical ingredient of meditation? Comparing the effects of spiritual meditation, secular meditation, and relaxation on spiritual, psychological, cardiac, and pain outcomes. J Behav Med. 2005;28(4):369-384.

21. Easwaran E. Mantram Handbook: A Practical Guide to Choosing Your Mantram and Calming Your Mind. 4th ed. Tomales, CA: Nilgiri Press; 2008.

22. Kabat-Zinn J. An outpatient program in behavioral medicine for chronic pain patients based on the practice of mindfulness meditation: theoretical considerations and preliminary results. Gen Hosp Psychiatry. 1982;4(1):33-47.

23. Chaoul MA, Cohen L. Rethinking yoga and the application of yoga in modern medicine. Cross Currents. 2010;60(2):144-167.

24. Larkey L, Jahnke R, Etnier J, Gonzalez J. Meditative movement as a category of exercise: implications for research. J Phys Act Health. 2009; 6(2):230-238.

25. Lan C, Chou SW, Chen SY, Lai JS, Wong MK. The aerobic capacity and ventilatory efficiency during exercise in Qigong and Tai Chi Chuan practitioners. Am J Chin Med. 2004;32(1):141-150.

26. Chan AW, Lee A, Suen LK, Tam WW. Tai chi Qigong improves lung functions and activity tolerance in COPD clients: a single blind, randomized controlled trial. Complement Ther Med. 2011;19(1):3-11.
27. Iyengar BKS. Light on yoga; yoga dīpikā New York: Schocken Books; 1966.

28. Zanoria SJ, ZuWallack R. Directly measured physical activity as a predictor of hospitalizations in patients with chronic obstructive pulmonary disease. Chron Respir Dis. 2013;10(4):207-213.

29. ZuWallack R. How are you doing? What are you doing? Differing perspectives in the assessment of individuals with COPD. COPD. 2007; 4(3):293-297.

30. Sackner MA, Watson H, Belsito AS, et al. Calibration of respiratory inductive plethysmograph during natural breathing. J Appl Physiol (1985). 1989;66(1):410-420.

31. Grossman P, Wilhelm FH, Brutsche M. Accuracy of ventilatory measurement employing ambulatory inductive plethysmography during tasks of everyday life. Biol Psychol. 2010;84(1):121-128.

32. Taylor S, Zvolensky MJ, Cox BJ, et al. Robust dimensions of anxiety sensitivity: development and initial validation of the Anxiety Sensitivity Index-3. Psychol Assess. 2007;19(2):176-188.

33. Osman A, Gutierrez PM, Smith K, Fang Q, Lozano G, Devine A. The Anxiety Sensitivity Index-3: analyses of dimensions, reliability estimates, and correlates in nonclinical samples. J Pers Assess. 2010;92(1):45-52.

34. Guyatt GH, Berman LB, Townsend M, Pugsley SO, Chambers LW. A measure of quality of life for clinical trials in chronic lung disease. Thorax. 1987;42(10):773-778.

35. Guyatt G. Measuring health status in chronic airflow limitation. Eur Respir J. 1988;1(6):560-564.

36. Walach H, Buchheld N, Buttenmüller V, Kleinknecht N, Schmidt S. Measuring mindfulness - the Freiburg Mindfulness Inventory (FMI). Pers Indiv Differences. 2006;40(8):1543-1555.

37. Eisendrath SJ, Delucchi K, Bitner R, Fenimore P, Smit M, McLane M. Mindfulness-based cognitive therapy for treatment-resistant depression: a pilot study. Psychother Psychosom. 2008;77(5):319-320.

38. Hintze J. PASS 2008 user's guide. Kaysville, UT: Number Cruncher; 2008.

39. Fischer MJ, Scharloo M, Abbink JJ, et al. Drop-out and attendance in pulmonary rehabilitation: the role of clinical and psychosocial variables. Respir Med. 2009;103(10):1564-1571.

40. Global Initiative for Chronic Obstructive Lung Disease. Global strategy for the diagnosis, management and prevention of chronic obstructive pulmonary disease. Global Initiative for Chronic Obstructive Lung Disease; 2014. Available from: http://www.goldcopd.org/guidelinesglobal-strategy-for-diagnosis-management.html. Accessed December $17,2014$.

41. Schaefer KE. Respiratory pattern and respiratory response to $\mathrm{CO}_{2}$. J Appl Physiol. 1958;13(1):1-14.

42. Creamer P, Singh BB, Hochberg MC, Berman BM. Sustained improvement produced by nonpharmacologic intervention in fibromyalgia: results of a pilot study. Arthritis Care Res. 2000;13(4):198-204.

43. Rosenzweig S, Reibel DK, Greeson JM, et al. Mindfulness-based stress reduction is associated with improved glycemic control in type 2 diabetes mellitus: a pilot study. Alt Ther Health Med. 2007;13(5):36-38

44. Sephton SE, Salmon P, Weissbecker I, et al. Mindfulness meditation alleviates depressive symptoms in women with fibromyalgia: results of a randomized clinical trial. Arthritis Rheumatism. 2007;57(1):77-85.

45. Baba K, Nitta R. Phase transitions in development of writing fluency from a complex dynamic systems perspective. Lang Learn. 2014;64(1):1-35.

46. Vetter G, Stadler M, Haynes JD. Phase transitions in learning. J Mind Behav. 1997;18(2-3):335-350.

47. Kelso JA. Instabilities and phase transitions in human brain and behavior. Front Hum Neurosci. 2010;4:23.

48. Fulambarker A, Farooki B, Kheir F, Copur AS, Srinivasan L, Schultz S. Effect of yoga in chronic obstructive pulmonary disease. Am J Ther. 2012;19(2):96-100.

49. Hoge EA, Bui E, Marques L, et al. Randomized controlled trial of mindfulness meditation for generalized anxiety disorder: effects on anxiety and stress reactivity. J Clin Psychiatry. 2013;74(8):786-792. 
50. Delmonte MM. Personality correlates of meditation practice frequency and dropout in an outpatient population. J Behav Med. 1988;11(6):593-597.

51. Wheaton MG, Deacon BJ, McGrath PB, Berman NC, Abramowitz JS. Dimensions of anxiety sensitivity in the anxiety disorders: Evaluation of the ASI-3. J Anxiety Dis. 2012;26(3):401-408.
52. Takahashi T, Murata T, Hamada T, et al. Changes in EEG and autonomic nervous activity during meditation and their association with personality traits. Int J Psychophysiol. 2005;55(2):199-207.

\section{Publish your work in this journal}

The International Journal of COPD is an international, peer-reviewed journal of therapeutics and pharmacology focusing on concise rapid reporting of clinical studies and reviews in COPD. Special focus is given to the pathophysiological processes underlying the disease, intervention programs, patient focused education, and self management protocols.
This journal is indexed on PubMed Central, MedLine and CAS. The manuscript management system is completely online and includes a very quick and fair peer-review system, which is all easy to use. Visit http://www.dovepress.com/testimonials.php to read real quotes from published authors.

\footnotetext{
Submit your manuscript here: http://www.dovepress.com/international-journal-of-chronic-obstructive-pulmonary-disease-journal
} 